\title{
ASPECTOS PSICOSSOCIAIS DA SAÚDE DO TRABALHADOR
}

Edith Seligmann-Silva

"Ali se é um verdadeiro escravo, não se pode dizer nada, a gente é

obrigado a ficar calado, mesmo esteja morrendo de cansaço"

(Ajudante industrial)

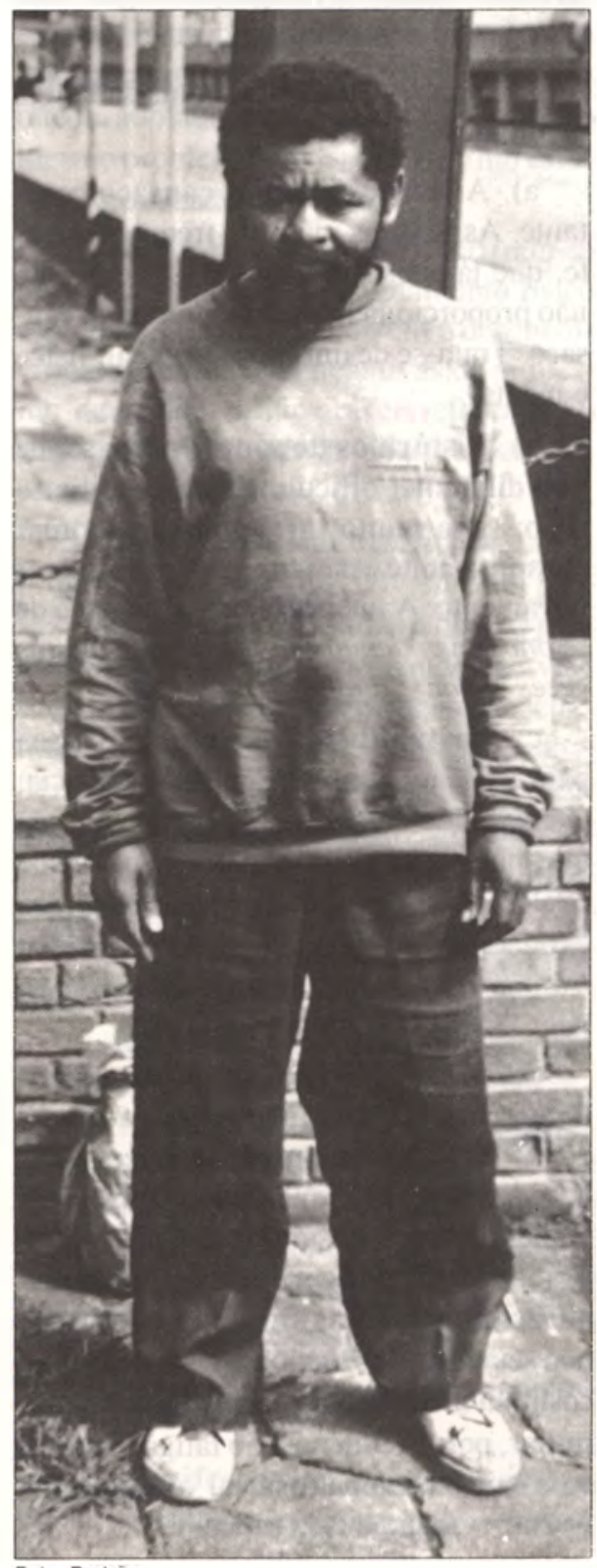

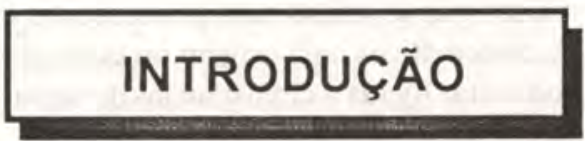

Neste artigo. trataremos principalmente da saúde em sua dimensão psicossocial. Mas convém esclarecer desde logo que é impossivel separar saúde psicossocial de saúde física, assim como é impossível dissociar corpo e mente. O sofrimento humano é um só: o que atinge o corpo, atinge a vida mental $\mathrm{c}$ a sociabilidade, sendo que a recíproca também é verdadeira.

Os impactos da migração sobre a saúde mental de quem vem trabalhar em terras estranhas é um assunto antigo e bastante polêmico.

Inicialmente era considerado que a migração sempre acarretava ataques à identidade e determinava vivências de insegurança, ocasionalmente perturbações vinculadas a estas vivências e a sentimentos de perda e/ou de medo do desconhecido. Mais recentemente, verifica-se que a situação política, sócio-econômica e familiar em que se processa a migração e a inserção em um novo contexto apresentam diferenças que se tornam decisivas para o grau de receptividade e segurança que serão vivenciados pelo migrante. A acolhidae as perspectivas percebidas com maior clareıa quanto ao futuro são elementos cruciais. Então, a accitação obtida pelo trabalhador migrante nos ambientes de vida e trabalho em que ingresse constituirá fator de grande importância para sua saúde psicossocial c para o desenvolvimento de uma nova vida.

\section{As situações de trabalho}

O que espera o trabalhador migrante, especialmente quando se trata de alguém que veio do campo para a cidade, sem ter tido oportunidade de obter capacitação para o desempenho de ocupações ditas “'modernas", são geralmente situações de trabalho bastante desfavoráveis à saúde. Procuraremos, a seguir, apresentar um resumo dos principais aspectos das situações de trabalho que devem ser considerados para entender os agravos sofridos pela saúde psicossocial dos trabalhadores.

Vale, de inicio, mencionar que o estudo das situações de trabalho envolve tanto as condições do ambiente físico, quimico e biológico do trabalho quanto a política de pessoal da empresa, o processo de trabalho e o tipo de controle a que os trabalhadores são submetidos. Importam igualmente os padrões de relações humanas e inter-hicrárquicas vigentes na empresa, a estrutura temporal do trabalho e os conteúdos das tarefas, além de outros aspectos organizacionais.

Na estrutura temporal do trabalho são considerados, entre outros componentes: a duração das jornadas; o regime diurno, noturno, ou em turnos de revezamento, dos horários de trabalho; os ritmos impostos ou não e sua intensidade, a qualidade c quantidade das pausas, os intervalos interjornadas e a folgas.

A caracterização das relações sociais de trabalho edos modelos de gerenciamento adotados são também da maior importân- 
cia. Pois tudo o que restringe a autonomia mental e corporal do trabalhador atua negativamente do ponto de vista dos interesses referidos à sua saúde.

Como já afirmamos acima, tudo o que afeta o corpo também afeta a vida mental e a sociabilidade. Portanto, quando o corpo é agredido por condições físicas como ruido, vibrações, falta de ventilação, temperaturas inadequadas para o ser humano; químicas (gazes ou susbtâncias tóxicas em suspensão no ar); ou mesmo biológicas (contaminação do ambiente por bactérias ou outros microorganismos capazes de causar doenças, por ex.), haverá repereussões psicológicas e sociais. Para os trabalhadores sem qualificação, principalmente, a doença costuma ser uma fonte de ansiedade e insegurança quanto à manutenção do emprego e da capacidade de exercê-lo.

Importantes interações ocorrem entre os diferentes aspectos organizacionais e também entre estes c os ambientais, nas situações concretas em que os trabalhadores estão mergulhados, em permanente interação uns com os outros e com a situação de trabalho. Assim, desenvolve-se um processo extremamente dinâmico $\mathrm{cm}$ que os trabalhadores atuam transformando as situações de trabalho ao mesmo tempo que também são transformados pelas mesmas e, muitas vezes, pelo desgaste que lhes vai sendo imposto.

Neste processo, ao longo da sucessão das semanas, meses e anos, mudam os modos de pensar, sentir e agir, enquanto a própria estrutura corporal vai sofrendo as alterações que simultaneamente advêm do envelhecimento, do trabalho e às vezes das outras esferas da vida que impõem carências, violênciasou, aocontrário, constróem fortalecimentos.

Ao mesmo tempo, individuos e coletivos de trabalho podem amadurecer cxperiências e desenvolver, solidariamente, modos de lidar com as pressões do cotidiano laboral.

Vale a pena pensar o quanto, na modernidade atual, estes processos são alterados pela rapidez das próprias mudanças tecnológicas e organizacionais, especialmente por aquelas que rompem a sociabilidade construída no convívio e na experiência compartilhada. Seriam exemplos os “enxugamentos" 'que, em nome da racionalização e da "qualidade total". lançam imensos contingentes humanos ao desemprego, ao trabalho informal ou à formas predadoras de terceirização.

\section{OS AGRAVOS}

Existc um grupo de problemas de saúde que vem sendo estudado com maior atenção no que diz respeito às suas vinculações com as situações de trabalho. Mencionaremos, a seguir, as principais características dos mesmos. Entretanto, não esgotaremos o assunto, pois existem muitos outros transtornos psicossociais c psicossomáticos cuja origem ou evolução pode estar ligada a circustâncias do trabalho.

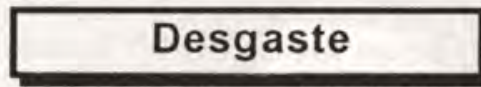

Osagravos psicossociais vinculados ao trabalho podem ser analisados em termo de desgaste.

Desgaste mental não significa necessariamente doença. Significa, essencialmente, perda - provisória ou definitiva - de algo que antes fazia parte do trabalhador e do seu mundo mental. Portanto, esse conceito inclui desde os desgastes literais, orgânicos, em que alterações psíquicas irão decorrer de lesões cercbrais provocadas por circunstâncias do trabalho - por exemplo intoxicações, atć perdas de outra ordem - como as perdas acarretadas para a identidade, para a densidade da própria vida afetiva ou para os projetos construidos tendo em vista ofuturo pessoal e da família.

Os estudos que identificam esses agravos estão surgindo em diferentes países do mundo e vários não foram ainda incluídos na classificação internacional de doenças (C.I.D). Outros obtiveram essa inclusão muito recentemente, na última classificação feita (CID-10), como é o caso da síndrome do "burn-out', Por isto, estamos colocando, em vários casos, as diferentes designações que estão sendo usadas para um mesmo quadro clínico.

1 - O cansaço patológico (Fadiga crônica. Fadiga industrial. Fadiga patoló- gica).

Os primeiros estudos sobre esse problema foram realizados na área industrial e por isto, durante certo tempo esta perturbação foi denominada "fadiga industrial' 'e descrita principalmente em operários submetidos a trabalho que demandava grandes esforços (principalmente físicos), em jornadas longas, e/ou em ritmo intensivo. Nos trabalhadores cujas atividades cram noturnas ou em turnos de revezamento, a ocorrência desta fadiga foi descrita por vários autores.

Em medicina, costuma designar-se síndrome um conjunto de sintomas, o que não corresponde à categorização como doença. Assim, a fadiga patológica tem sido considerada uma sindrome.

As manifestações principais da fadiga patológica são:

a) A sensação de um cansaço constante. As pessoas referem, frequentemente, que já acordam cansadas, que o sono não proporciona mais a superação do cansaço. Trata-se de um cansaço geral: físico e mental.

b) Distúrbios do sono. Podem ser de tipo diferente: dificuldade de conciliar o sono; sono muito interrompido; acordar durante a noite e não conseguir adormecer novamente. A queixa mais frequente é de "sono leve demais", "acordar muitas vezes durante a noite",

c) Irritabilidade intensa. A pessoa passa a sentir que tem menos paciência, que explode com mais facilidade ou que tem que fazer enorme esforço para não cxplodir. Muitas vezes o que a pessoa expressa é: " agora me irrito e até descontrolo por coisas que antes nem me afetavam',

d) Desânimo. Este desânimo, referido geralmente como "perda de disposição", reflete-se num esvaziamento das atividades e relacionamentos sociais. A tendência é de não sair de casa nas folgas, abandonar esportes, participação em iniciativas comunitárias, recusar tudo o que não seja rotina obrigatória. Este desânimo costuma afetar particularmente a vida familiar, pois a tendência do fatigado crônico é um retraimento social que costuma frustar o cônjuge e os filhos. 
Dores de cabeça, dores no corpo, perda de apetite, são outras manifestações que podem ou não aparecer nestes casos da síndrome de fadiga crônica vinculada ao cansaço acumulado.

2 - Estafa (Esgotamento profissional ou sindrome do "burn-out")

A designação " burn-out" corresponde em português a incêndio, no sentido de algo que "queima até o fim". Em "psicopatologia do trabalho", Freudenberger é o psicanalista que adota este termo, que vem se divulgando muito no Canadá e nos países de língua inglesa. "Burn-out" seria uma espécie de incêndio arrasador das energias, do ânimo, das expectativas e da própria auto-estima. Um esgotamento profissional, na expressão que foi adotada $\mathrm{em}$ francês para designar o mesmo problema. No Brasil, o termo estafa já vem sendo utilizado.

De acordo com Chanlat (1990) trata-se de "uma síndrome de esgotamento físico e emocional, na qual ocorrem o desenvolvimento de imagens negativas de si mesmo, de atitudes desfavoráveis referentes ao trabalho e uma perda de interesse $\mathrm{cm}$ relação aos clientes." (p.120)

A síndrome tem sido descrita em várias profissões e muito especialmente $\mathrm{em}$ pessoas que prestam cuidados a outras pessoas, na área de educação, saúde e serviço social. Geralmente são pessoas especialmente idealistas e dedicadas ao seu trabalho, muito exigentes em relação a si mesmas, que sacrificam muito o próprio bem estar. Fortes decepções e a ausência de reconhecimento costumam ser elementos importantes no desencadeamento da sintomatologia, na qual se verifica:

a) Manifestações depressivas caracterizadas pela vivência de um estado de saturação emocional em que o profissional se sente impossibilitado de suportar novos encontros com as pessoas cujas necessidades procurava atender.

Idéias de fracasso: a pessoa se autoacusa como incompetente.

b) Perda do autocontrole emocional.

c) Manifestações gerais de nervosismo: irritabilidade; perturbações do sono; inquictação.

Vale mencionar que esta síndrome também tem sido descrita entre executivos e em algumas outras atividades além das acima mencionadas.

Existem vários estudos sobre enfermeiras e outros profissionais que. tendo grande e permanente convívio com o sofrimento humano, estão particularmente expostos a esta sindrome, principalmente se as condições em que trabalham prejudicam o êxito de seus esforços.

\section{3 - Neuroses traumáticas}

Uma experiência na qual a pessoa vivencia uma ameaça intensa à própria vida é o exemplo mais comum do que se considera "experiência traumatizante". Mas também quando uma cena de horror e sofrimento é presenciada, quem a assiste pode ficar traumatizado - é o que muitas vezes acontece com trabalhadores que assistem a um acidente fatal.

Bancários que vivem o terror de um assalto às agências em que trabalham; maquinistas que são ameaçados e mesmo agredidos fisicamente por pessoas revoltadas com os atrasos dos trens, às vezes em situações de grave tumulto - estes são alguns exemplos de exposição a ocorrências potencialmente traumatizantes. Felizmente, nem todos desenvolvem neuroses pós-traumáticas $\mathrm{em}$ tais circunstâncias, $\mathrm{e}$ justamente a análise dos "fatores de proteção" (psicológicos e sociais) vem merecendo muita atenção nas práticas preventivas.

No quadro clínico das neuroses traumáticas destacam-se os chamados fenômenos de revivescência $\mathrm{cm}$ que a pessoa revive psicologicamente $o$ acontecimento traumático. A imagem do acidente, ou do assalto, por exemplo, vemà mente sem que o individuo possa controlar essa revivescência. que se acompanha de grande mal-estar. Também costumam ocorrer pesadelos em que o fato traumático aparece.

Além das neuroses traumáticas, outras neuroses podem desenvolver-se articuladas às situações de trabalho. Mesmo quando a origem primeira da neurose se encontra na fase infantil da vida, vivências do cotidiano do trabalho podem desencadear ou agravar a sintomatologia.

\section{4-O embotamento afetivo:} as síndromes da insensibilidade (Alexitimia, Normopatias)

Entramos aqui num dos assuntos mais atuais e importantes da psicopatologia do nosso tempo. Trata-se justamente do que acontece nas situações de trabalho nas quais a afetividade tende a ser sufocada ou expulsa em nome da racionalidade.

Alexitimia significa distanciamento em relação aos próprios sentimentos. A a partir da indiferença afetiva em relação a si própria, a pessoa também se torna insensivel em relação aos demais. Ao mesmo tempo, o individuo permanece, de um modo correto, embora mecânico, realizando as operações de seu trabalho. Alguns autores evocam, para descrevera alexitimia, a imagem de um relógio ou de um robô: funciona com precisão, mas sem sentimentos. É o que tem sido chamado "vida operativa", isto é, a pessoa "opera", funciona como máquina.

Pressões organizacionais e especialmente exigências de atividades mentais de grande densidade que requerem alta concentração, figuram entre as determinações mais estudadas do fenômenoda alexitimia, quando este emerge a partir de situações de trabalho. É como se a pessoa tivesse que rechaçar para um compartimento distante suas fantasias e sentimentos, a fim de se centrar no desempenho de suas atividades.

A alexitimia talvez seja uma espécie de defesa pela qual as pessoas se protegem diante de agressões à sua identidade. Está bem comprovado que também significa um grande risco de ocorrência de enfarte súbito do coração e de outras doenças.

Este tipo de problemática tem merecido um grande número de estudos e apresenta grandecomplexidade. Principalmente nas atividades informatizadas e automatizadas, portanto, naquelas mais estimuladas no mundo moderno, têm sido realizadas constatações a respeito. Mas tudo indica que a "culpa" da alexitimia não é tanto das tecnologias sofisticadas e sim, principalmente, das formas como as atividades são organizadas e controladas.

Numa época em que a ênfase na cha- 
mada "qualidade total" percorre as cmpresas, a questão da qualidade de vida no trabalho emerge como fundamental, tendo em vista todo o conjunto de agravos psicossociais que podem surgir conectados ao trabalho. Mas o caso das sindromes de insensibilidade passa a ser uma preocupação não apenas de ordem psicológica ou médica, mas também, de ordem social c política - se refletirmos o que pode significar, em nivel nacional ou mundial, a cscalada da insensibilidade.

\section{5 - Alcoolismo vinculado a situa- ções de trabalho \\ Oalcoolismo é um dos maiores proble- mas de saúde pública do nosso tempo.}

A depedência de bebidas alcoólicas. assim como a dependência em relação às drogas em geral - das quais não trataremos aqui, embora às vezes também estejam relacionadas ao trabalho - podem ter origem em aspectos psicológicos profundos $\mathrm{c}$ complexos. Entretanto, apesar de reconhecida, atualmente, a multicausalidade do problema, o fato é que $\mathrm{cm}$ numcrosos tipos de ocupação e de situação de trabalho, verifica-se uma importante correlação entre aspectos do trabalho e o uso cxcessivo de bebidas alcoólicas.

Para que se compreenda porque isto acontece, entre outros pontos, vale destacar dois:

$\left.1^{\circ}\right) \mathrm{O}$ álcool possui algumas ações bem conhecidas: euforizante (estimula; proporciona sensação de alegria) e relaxante (diminui momentaneamente a tensão). Não falaremos aqui das indiscutiveis ações prejudiciais à mente $\mathrm{e}$ ao organismo $\mathrm{em}$ geral, queremos apenas lembrar que as duas ações acima citadas são justamente bastante procuradas pelos que buscam prazer ou um modo de diminuir tensões derivadas do trabalho. Numa pesquisa feita entre pessoas muito pobres e que realizavam trabalho especialmente penoso, à indagação da razão pela qual procuravam beber era frequentemente: "Porque é o (único) gosto que a gente pode ter!' Deve ser lembrado também que a cuforia pode ser buscada para tentar enfrentar momentos desagradáveis e sombrios. Isto foi constatado com trabalhadores que lidam com cadáveres ou materiais repugnantes (lixo e dejetos em geral), em diferentes estudos. Nestas pes- quisas. frequentemente os trabalhadores declaravam que a única maneira que encontravam para suportar tais atividades era ingerindo bebidas alcoólicas. O álcool também é usado para vencer a insônia. o que pode vir, com o tempo, a causar dependência. $2^{\circ}$ ) As práticas de consumo de bebidas alcoólicas possuem importantes significados em diferentes culturas. Muitas vezes a idéia de virilidade é associada a este consumo ("Quem é homem. bebe"). Por outro lado, o uso de bebidas se faz também em rituais comunitários de muitos

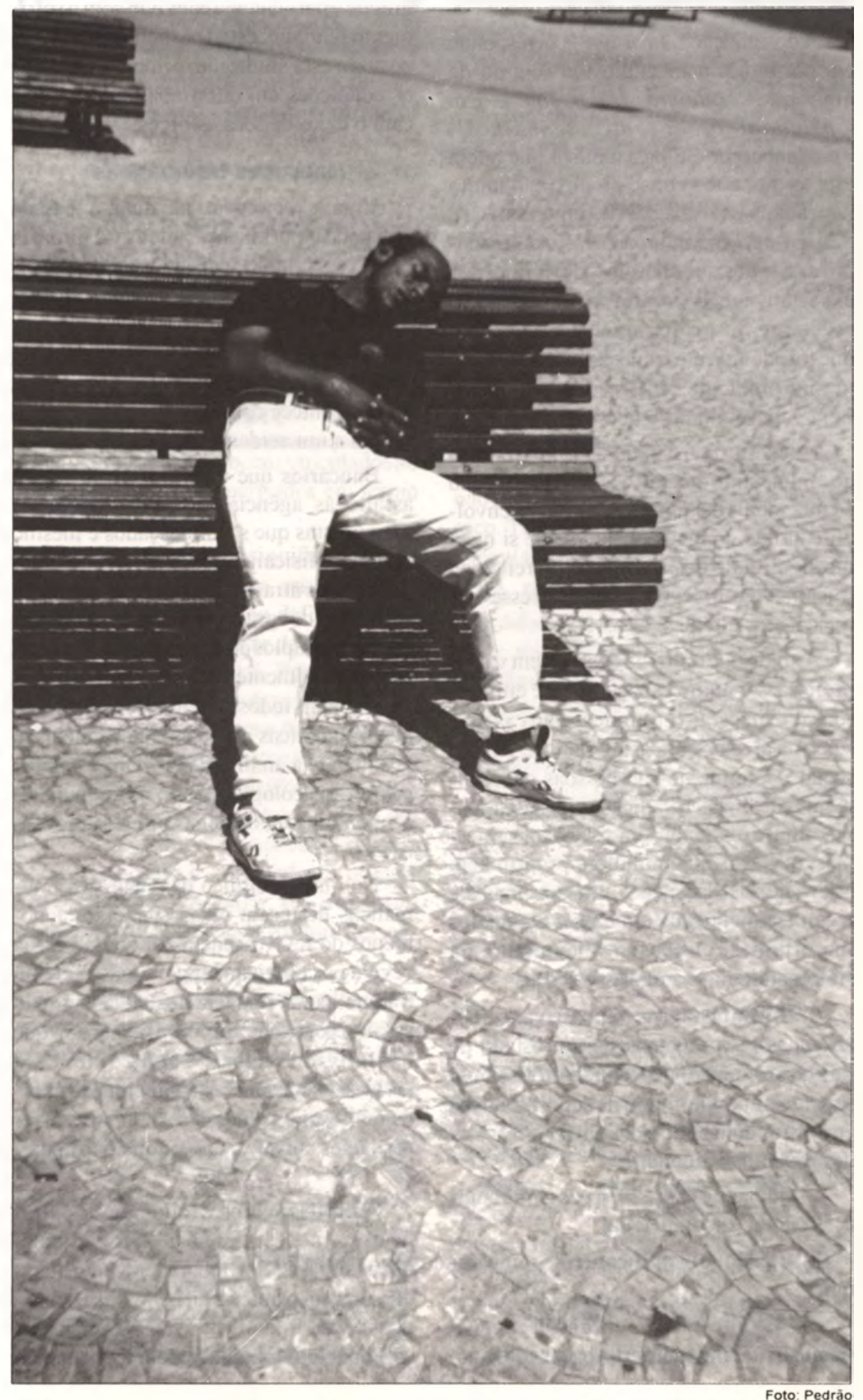


povos e é muito forte a idéia de que "companheiros bebem juntos". Assim, para fazer parte de determinados grupos. as pessoas se sentem obrigadas a participar em reuniões onde todos utilizam bebidas alcoólicas. Portanto, deve ser levado em conta o sentido cultural da bebida.

Do que ficou dito acima, pode-se inferir que são mútiplas as situações de trabatho que podem facilitar a instalação do hábito de consumo das bebidas, com posterior dependência.

As situações de trabalho em que ocorre intenso isolamento físico - ficando o trabalhador sozinho por muitas horas - também podem gerar sensações insuportáveis de ansiedade ou solidão nas quais a bebida alcoólica é procurada como "calmante".

Como o álcool também é conhecido como "desinibidor", existem pessoas que. em certas ocupações, o procuram para enfrentar ocasiões em que necessitam ser "sociáveis" e falar com desembaraço.

Mas são. sobretudo, as situações em que a dignidade é atacada, quando o trabalhador sofre desconsiderações reiteradas e mesmo humilhação, c ao mesmo tempo não possui possibilidade de reagir sob pena de perder o emprego, as que configuram risco para desencadeamento do alcoolismo. Neste caso, a bebida scrá usada com diferentes e simultâneas finalidades: buscar um estado de entorpecimento para acalmar a dor da humilhação, atacar a si mesmo e o mundo percebido como injusto e cruel. Evidentemente. estes mecanismos muitas vezes não são conscientes.

Verifica-se, assim, que quando existe uma situação $\mathrm{em}$ que o trabalho é penoso ou repugnantc, além da superação das condições objetivas deste trabalho, os trabalhadores devem sentir-sevalorizados no desempenho de suas atividades.

\section{COMENTÁRIOS FINAIS}

A vinculação entre determinadas situações de trabalho $\mathrm{e}$ a constituição de agravos à saúde mental é questão cientificamente comprovada. Mas o assunto tem sido sistematicamente obscurecido quando se trata de buscar a aplicação dos conhecimentos já consolidados ao mundo do trabalho.

É também verdade que, a partir do trabalho, as pessoas podem conquistar realização pessoal e construir um sentido para a própria vida. Deste modo, o trabalho torna-se fonte de prazer c auto-estima, gerando estímulos para novos desenvolvimentos e iniciativas pessoais e coletivas. Nesic caso, pode-se afirmar que o trabalho corresponde a um valioso fator de promoção de saúde mental e psicossocial. Este é o "lado positivo" do trabalho que costuma ser o mais ressaltado, valorizado e divulgado. Entretanto, a exaltação acrítica dos aspectos "bons" do trabalho vem justamente impedindo que se realizem ações eficazes para vencer os aspectos penosos. desumanos e mesmo adoecedores $\mathrm{e}$ destrutivos que estão presentes em numerosas situações de trabalho.

Por isto mesmo é que. neste artigo, pretendemos examinar alguns destes aspectos "negativos" sionam, buscando, ao mesmo tempo, considerar as possibilidades de superação de tais males.

O conflito de interesses que vem retardando a divulgação e a aplicação dos resultados das pesquisas desenvolvidas na temática da Psicopatologia do Trabalho é bastante claro. As mais relevantes descobertas cientificas neste campo demonstram que o "foco central" $\mathrm{em}$ que se originam as tensõcs eagravos psicossociais, nas situações de trabalho, está na organização do mesmo. E o desafio de transformar esta organização, justamente, levanta poderosas resistências no interior das empresas. Resistências que, na maioria das vezes, se articulam a temores de perdas econômicas e de poder. Presentemente. em especial nos países de economia central do primciro mundo, os dirigentes de empresas que se dispõem a uma análise mais profunda, adotam uma visão mais avançada e começam a vencer estes temores pois no momento histórico $\mathrm{cm}$ que cada vez. mais o trabalho mental substitui otrabalho manual, o trabalhador necessariamente tem que ser reconhecido como pessoa dotada de pensamento, sentimentos e dignidade. Eo respeito ao trabalhador pensantc torna-se uma necessidade para conquistar a efetiva adesão e compromisso do mesmo com a produção. Este respeito, infelizmente ainda ausente em grande número de situações de trabalho, é o elemento central da dinâmica em que são gerados, simultâneamente, a ética do trabalho e a efetiva qualidade de vida no trabalho. A qualidade de vida no trabalho é uma parte essencial do caminho que conduz aos ga nhos de qualidade, tão tenazmente perseguidos pelas empresas.

Nas diferentes pesquisas de campo realizadas no Brasil dentro de estudos voltados para as questões da Saúde Mental e Psicossocial no Trabalho, a ausência do reconhecimento e até do respeito humano foi uma constante em grande parte do material levantado a partir da fala dos assalariados de diferentes setores. A própria condição humana, segundo muitos depoimentos, era percebida como não considerada, tal como expresso por trabalhadores industriais que mencionam sentir-se "tratados como animais".

Outras vezes, a representação evocada pelos trabalhadores, era a de alguém desprovido de cidadania - a figura do escravo.

Na presente fase, os avanços da democracia em nosso país necessariamente deverão incluir também a transformação $\mathrm{cm}$ que sejam estabelecidos o respeito humano co reconhecimento em um espaço de livre expressão, no interior dos ambientes de trabalho, proporcionando ao mesmo tempo novos fundamentos para a esperança, a criatividade e um desenvolvimento que seja simultaneamente econômico e humano.

"Edith Seligmann-Silva é Prof" da Faculdade de Medicina da USP e da Escola de Administração de Empresas da Fundação Getúlio Vargas. Autora de Desgaste Mental no Trabalho Dominado, recentemente editado pela Eal. UFRJ/Corte:

\section{BIBLIOGRAFIA}

1. CHANLAT, J.F - Thèories du stress el psychopathologie du travail - Prevenir (20): 117-126. 1990

2. DEJOURS, C - De la Psychopathologie a la Psychodynamique du Travail. in: Dejours, C, - TravailUsure Mentale, Bayard ed .pp. 205-259. Paris, 1993 3. FREUDENBERGER, H.J - L'Epuisement Professionnel: la "brülure interne" - Gaelan Morin ed. - Quebec, 1987

4. FRANKENHAEUSER, M - Coping with stress at work. Int. J.Health Serv. 11 (4): 491-510, 1981

5. SELIGMANN-SILVA, E. - Psicopatologia e Psicodinámica do Trabalho - In: Mendes, R.. Patologias do Trabalho, Ed, Alhenéu, Rio, 1994 